\title{
TANTANGAN PELAYANAN PENGGEMBALAAN HAMBA TUHAN DALAM ZAMAN NOW
}

\author{
Agung Gunawan
}

\begin{abstract}
Abstrak:Dalam zaman now, hamba Tuhan diperhadapkan dengan berbagai macam perubahan yang begitu cepat dan tantangan yang begitu banyak dalam pelayanannya.
\end{abstract}

Hamba Tuhan diharapkan dapat memenuhi kebutuhan jemaat yang sangat kompleks. Hamba Tuhan bukan hanya dituntut untuk dapat memenuhi kebutuhan spiritual jemaatnya, namun juga dituntut untuk dapat memenuhi kebutuhan-kebutuhan yang lain dari jemaatnya.

Ada banyak gereja yang memperlakukan hamba Tuhannya seperti karyawan atau pegawai yang dapat diperintah untuk melakukan segala sesuatu yang diminta oleh majikannya. Kadang apa yang diminta tidak sesuai dengan tugas dan tanggungjawab seorang hamba Tuhan.

Hamba Tuhan juga dituntut menjadi orang yang serba bisa dalam pelayanan yang diembannya. Hamba Tuhan dituntut untuk dapat menjalankan semua tugas pelayanan penggembalaan dengan maksimal. Apabila hamba Tuhan gagal dan lalai untuk menjalankan kewajibannya dengan maksimal maka akan menghadapi berbagai macam konsekuensi, mulai diperingatkan hingga diberhentikan dari pelayanannya.

Semua tantangan dan tuntutan dalam pelayanan tidak boleh membuat hamba Tuhan tawar hati dan mengambil keputusan untuk mundur dan meninggalkan pelayanan. Oleh karena itu, hamba Tuhan harus mempersiapkan diri dengan baik dan melengkapi diri 
116 Tantangan Pelayanan Penggembalaan Hamba Tuhan Zaman Now

dengan segala macam keterampilan dan kemampuannya baik dalam hal berkhotbah, melayani visistasi, melayani orang yang sulit dalam gereja, melayani kaum LGBT, dan melayani kaum muda agar ia akan dapat menjawab kebutuhan jemaat dan mampu bertahan dalam arena dunia pelayanan yang semakin kompetitif dalam zaman now. Hamba Tuhan harus menjalani tugas dan panggilannya dengan setia sampai Tuhan datang.

Kata-kata kunci: Zaman now, hamba Tuhan, tantangan, khotbah, visitasi, orang sulit, pelayanan kaum muda

Abstract:In this now age, God's servants are faced with such rapid changes and enormous challenges in their ministry. God's servant is expected to meet the very complex needs of their congregations. God's servants are not only required to be able to meet the spiritual needs of their congregation, but are also required to be able to meet the other needs of their congregations.

There are many churches that treat their servants as employees who can be commanded to do everything what their employers ask for. Sometimes what are requested do not match the duties and responsibilities of God's servants.

God's servants are also required to be a versatile person in their ministry. God's servants are required to be able to carry out all the duties of pastoral ministry with the maximum. If God's servants fail and neglect to fulfill their duty to the maximum then they will face various consequences, begin to be warned and also to be discharged from their ministry.

All challenges and demands in the ministry should not make God's servants discouraged and decide to retreat and to leave their ministry. Therefore, God's servants should be well prepared and equiped themselves with all skills and abilities including preaching, 
visiting, serving the difficult people in the church, serving the $L G B T$, and serving the youth, so that they will be able to answer the needs of the congregations and able to survive in the increasingly competitive world of ministry in the now age. God's servants must do their duty faithfully until the Lord comes.

Keywords: Now age, servants of God, challenges, preaching, visitation, difficult people, youth ministry

\section{PENDAHULUAN}

Gereja saat ini sedang berada di zaman now yaitu suatu kondisi zaman yang penuh dengan berbagai macam perubahan yang begitu cepat dan tantangan yang begitu banyak. Jemaat Tuhan sedang diperhadapkan dengan berbagai macam perubahan yang serba cepat dan tantangan hidup yang serba kompleks. Dalam kondisi zaman seperti ini hamba Tuhan juga dituntut untuk dapat mengikuti perkembangan zaman. Tantangan dan tuntutan hamba Tuhan dalam zaman now mengalami perubahan yang sangat cepat, signifikan dan kompleks. Itulah sebabnya hari ini tidak banyak orang yang mau mempersembahkan diri menjadi hamba Tuhan.

Bagi orang-orang yang telah memilih untuk menjawab panggilan Tuhan menjadi hamba Tuhan atau gembala dalam sebuah gereja harus menjalani tugas dan panggilannya dengan setia sampai Tuhan datang. Perubahan yang cepat dan tantangan yang kompleks tidak boleh membuat hamba Tuhan tawar hati dan mengambil keputusan untuk mundur dan meninggalkan pelayanan. Semua tantangan harus menjadi suatu pemicu bagi hamba Tuhan untuk dapat meningkatkan kualitas pelayanannya agar supaya pelayanannya diberkati dan menjadi berkat bagi jemaat yang dilayani. 
118 Tantangan Pelayanan Penggembalaan Hamba Tuhan Zaman Now

Dalam zaman now, hamba Tuhan juga akan diperhadapan dengan kondisi pelayanan di mana tidak ada batasan-batasan yang jelas tentang tugas dan tanggungjawabnya di dalam gereja. Setiap anggota jemaat memiliki harapan yang berbeda-beda bagi hamba Tuhannya. Ada yang menginginkan hamba Tuhannya menjadi seorang pengkhotbah yang baik. Ada yang mengharapkan hamba Tuhannya menjadi seorang konselor yang baik. Ada jemaat yang merindukan hamba Tuhannya menjadi seorang yang mampu melakukan visitasi dengan baik kepada jemaat. Ada jemaat yang menginginkan hamba Tuhannya menjadi seorang yang dapat mencari dana bagi pemenuhan kebutuhan gereja. Ada masih banyak harapan-harapan yang lainnya yang harus dipenuhi oleh seorang hamba Tuhan. Ini adalah kondisi dan tuntutan pelayanan gereja dalam zaman now yang harus dipenuhi oleh seorang hamba Tuhan. Hamba Tuhan dituntut menjadi orang yang serba bisa dalam pelayanan yang diembannya. Hamba Tuhan harus siap memenuhi tuntutan ini atau kalau tidak maka ia akan tersisih dalam arena dunia pelayanan.

Ada pula gereja-gereja yang menganggap hamba Tuhannya seperti karyawan atau pegawai yang dapat diperintah untuk melakukan segala sesuatu yang diminta oleh majikannya karena mereka merasa menggaji hamba Tuhan dengan nominal yang cukup besar. Kadang permintaan mereka tidak sesuai dengan tugas dan tanggung jawab sebagai hamba Tuhan. Hal ini seringkali menimbulkan dilema bagi hamba Tuhan. Disatu sisi apa yang diperintahkan untuk dilakukan tidak sesuai dengan tugas dan kewajiban seorang hamba Tuhan. Namun disisi lain apabila hamba Tuhan tidak melakukannya maka ia akan menghadapi konsekuensi ditegur atau bahkan mungkin diberhentikan dari pelayanannya di gereja tersebut. Ini adalah beberapa tantangan dan tuntutan yang dihadapi oleh hamba Tuhan dalam zaman now. 
Dalam zaman now ini, hamba Tuhan yang melayani sebagai gembala di gereja memiliki banyak dimensi tanggung jawab dalam pelayanannya. Hamba Tuhan sebagai gembala umat bukan hanya dituntut untuk dapat memenuhi kebutuhan spiritual jemaatnya, namun juga dituntut untuk dapat memenuhi kebutuhan-kebutuhan yang lain dari jemaat yang digembalakan. Hamba Tuhan dituntut untuk dapat menjalankan semua tugas pelayanan penggembalaan dengan maksimal. Apabila hamba Tuhan gagal dan lalai untuk menjalankan kewajibannya dengan maksimal maka akan ia akan terancam kehilangan pelayanan.

Oleh sebab itu, seorang hamba Tuhan harus mempersiapkan diri dengan baik dan melengkapi diri dengan segala macam keterampilan dan kemampuan. Seorang hamba Tuhan tidak boleh puas diri dengan apa yang telah dimiliki. Ia harus terus menuntut diri dan terus belajar serta melengkapi diri dengan banyak kemampuan agar ia akan dapat menjawab kebutuhan jemaat dan mampu bertahan dalam arena dunia pelayanan yang semakin kompetitif dalam zaman now.

Selain itu, seorang hamba Tuhan juga harus belajar untuk rendah hati sehingga rela melakukan tuntutan gereja yang mungkin tidak sesuai dengan tugas dan kewajiban hamba Tuhan. Sebagai hamba Tuhan kita harus meneladani Kristus yang mau merendahkan diri-Nya sedemikian rupa. Alhasil Tuhan meninggikan Kristus. Demikian halnya dengan hamba Tuhan. Mungkin kita tidak dihargai pelayanan kita oleh gereja. Namun Tuhan Yesus sang Gembala Agung dan Tuan kita akan menghargai kita. Oleh sebab itu, hamba Tuhan harus berdiri teguh, jangan goyah, dan terus giat dalam melakukan perkerjaan Tuhan karena semua jerih payahnya tidak akan sia-sia (1 Korintus 15:58). 
120 Tantangan Pelayanan Penggembalaan Hamba Tuhan Zaman Now

Ada beberapa elemen dalam pelayanan hamba Tuhan yang harus menjadi perhatian yang serius agar supaya pelayanan Hamba Tuhan sebagai gembala jemaat dapat menjawab kebutuhan jemaat Tuhan dalam zaman now.

\section{Hamba Tuhan dan Khotbah}

Berkhotbah merupakan tugas paling sentral dan utama dalam pelayanan seorang hamba Tuhan. Keberhasilan dan kegagalan seorang hamba Tuhan seringkali diukur dengan kemampuannya menyampaikan kebenaran Firman Tuhan di atas mimbar. Berkhotbah merupakan sebuah tugas yang besar, berat serta melelahkan bagi seorang hamba Tuhan dalam gereja. Apabila seorang hamba Tuhan berkhotbah dua kali dalam seminggu maka ia harus mempersiapkan dan menyampaikan khotbah sekitar seratus kali dalam setahun. Seorang hamba Tuhan harus menginvestasikan waktunya dan energinya yang cukup banyak untuk mempersiapkan khotbah yang baik dan benar. Hamba Tuhan adalah pelayan dari Firman Ilahi. ${ }^{1}$

Dalam zaman now, jemaat membutuhkan khotbah yang bermutu yang dapat menjadi makanan rohani yang membawa pertumbuhan rohani menuju kepada kedewasaan iman mereka. Jemaat diperhadapkan dengan ajaran-ajaran dan falsafah-falsafah hidup yang menyesatkan yang ditawarkan oleh dunia. Banyak jemaat yang terbawa oleh arus pengajaran dunia dan mengalami dekadensi spiritual. Oleh sebab itu, hamba Tuhan memiliki tanggung jawab yang besar untuk memberikan makanan rohani yang sehat agar jemaat dapat mengalami pertumbuhan rohani dari hari ke hari sehingga mereka mengalami kedewasaan rohani. Realita menunjukkan bahwa banyak jemaat Tuhan yang mengeluh

\footnotetext{
${ }^{1}$ H. de Leede, and F.Stark, "Protestant Preaching: Its Strength and Weaknesss" ,Calvin Theological Journal Vol 50. No.1(2015), 43.
} 
tidak mendapatkan apa-apa dari khotbah gembalanya digereja. Mereka merasa khotbah yang disampaikan tidak ada isinya seperti makanan yang tidak ada gizinya. Akibatnya jemaatnya tidak mengalami pertumbuhan rohani. Ini harus menjadi perhatian yang serius bagi hamba Tuhan dalam mempersiapkan khotbahnya.

Jemaat Tuhan dalam zaman now juga merindukan khotbahkhotbah yang dapat menjawab masalah-masalah praktis yang dihadapi oleh jemaat dalam kehidupan sehari-hari. Sangat disayangkan hari ini banyak hamba-hamba Tuhan yang kurang dapat memberikan makanan rohani yang menjawab kebutuhan domba-dombanya melalui khotbah yang disampaikan diatas mimbar. Banyak jemaat yang merasakan bahwa khotbah-khotbah yang disampaikan oleh hamba Tuhannya terlalu idealis dan filosofis yang tidak relevan sama sekali dengan pergumulan hidup yang dialami oleh jemaat sehari-hari. Mereka merasa tidak mendapatkan sesuatu "berkat" rohani dari khotbah yang disampaikan oleh hamba Tuhannya.

Ada dua macam reaksi jemaat terhadap khotbah hamba Tuhan. Sebagian jemaat menerima saja dan merasa tidak ada masalah walaupun rohaninya tidak bertumbuh. Namun ada jemaat yang merasa kurang puas dan "jajan” di gereja lain. Ini adalah fenomena yang banyak terjadi dalam gereja-gereja protestan zaman now. Apabila hal ini terjadi gembala tidak boleh menyalahkan jemaatnya. Para gembala gereja harus introspeksi diri dan memperbaiki khotbahnya.

Selain daripada itu, melalui khotbahnya seorang hamba Tuhan memiliki tanggung jawab untuk berani menyuarakan kebenaran kepada jemaat yang dilayani dengan menegur dan mengingatkan jemaat yang melakukan dosa. Orang yang telah percaya dan menerima Tuhan Yesus sebagai Tuhan dan Juru 


\section{Tantangan Pelayanan Penggembalaan Hamba Tuhan Zaman Now}

selamatnya seharusnya hidup dalam kekudusan yaitu hidup terpisah atau berbeda dengan dunia. (Roma 12:2). Namun realita menunjukkan bahwa banyak orang-orang Kristen yang hidup menyimpang dari kehendak Tuhan dan lebih tertarik oleh tawaran dunia yang sangat menarik.

Zaman now menawarkan berbagai macam falsafah hidup yang menarik kepada manusia yang bertentangan dengan prinsipprinsip Firman Tuhan. Zaman now menawarkan falsafah materialisme yang mengajarkan bahwa materi atau uang adalah segala-galanya. Dengan memiliki uang, maka manusia akan dapat berbuat apa saja dan memiliki kuasa terhadap orang lain. Oleh sebab itu, manusia harus berlomba-lomba mencari dan mengumpulkan harta sebanyak-banyaknya dalam dunia ini dengan segala cara. Falsafah ini menyebabkan manusia dalam zaman now ini menghalalkan segala cara untuk mendapatkan uang melalui korupsi, manipulasi, penipuan, dan lain-lain.

Zaman now juga mengajarkan falsafah Hedonisme yang mengatakan bahwa kesenangan hidup adalah segala-galanya. Dalam hidup ini yang penting happy. Hedonisme mendorong manusia untuk mencari kenikmatan hidup dengan bebas tanpa harus mempedulikan norma-norma budaya maupun agama. Akibatnya banyak anak-anak muda jatuh dalam pergaulan bebas dan free sex. Tidak sedikit pula anak-anak muda yang terjerumus dalam penyalahgunaan narkoba. Falsafah yang ditawarkan oleh zaman now ini ternyata juga telah mempengaruhi orang-orang Kristen. Tidak sedikit pengurus gereja dan anggota jemaat yang terbawa oleh arus falsafah zaman now dan jatuh dalam dosa materialisme dan hedonisme.

Seorang hamba Tuhan harus berani tampil untuk secara tegas menyuarakan kebenaran dengan mengingatkan dan menegur dosa dengan kasih. Seorang hamba Tuhan memiliki peran yang sangat 
besar untuk membawa jemaatnya berbalik dari dosa dan hidup sesuai dengan kehendak Tuhan.

Tugas ini tidak mudah karena hamba Tuhan bukanlah manusia yang sempurna yang kadang juga dapat jatuh kedalam dosa. Hamba Tuhan juga bisa terpengaruh oleh falsafah materialisme dan hedonisme. Tetapi hal itu tidaklah menjadi alasan bagi seorang hamba Tuhan untuk tidak berani menjalankan tugas kenabiannya dalam menyatakan kebenaran dengan menegur dan menyadarkan jemaat yang melakukan dosa. Seperti seorang dokter yang harus berani mengingatkan pasiennya untuk menjaga kesehatan walaupun dirinya sendiripun sebagai dokter juga bisa sakit seperti pasiennya. Oleh sebab itu, seorang hamba Tuhan dalam mengemban tugas kenabiannya harus memohon kekuatan dan pertolongan Tuhan serta berusaha semaksimal mungkin untuk tidak terpengaruh oleh arus zaman now dan dapat menghindari dosa.

Ini adalah tantangan bagi hamba Tuhan dalam menyampaikan khotbah diatas mimbar dengan baik dan benar yang dapat memberi makanan rohani yang dibutuhkan dan dapat menjawab segala kebutuhan domba-dombanya. Apabila seorang hamba Tuhan lalai untuk mempersiapkan dan menyampaikan khotbah secara baik dan benar maka tanggung jawabnya bukan hanya kepada manusia tetapi juga kepada Tuhan Yesus Sang Gembala Agung.

\section{Hamba Tuhan dan Pelayanan Visitasi}

Pelayanan visitasi juga membutuhkan perhatian yang khusus dari seorang hamba Tuhan yang melayani sebagai gembala. Dalam zaman now, jemaat Tuhan sedang berhadapan dengan berbagai macam pergumulan hidup. Banyak jemaat yang mengalami 


\section{Tantangan Pelayanan Penggembalaan Hamba Tuhan Zaman Now}

pergumulan berkaitan dengan masalah ekonomi, masalah keluarga, masalah kesehatan, dan berbagai macam pergumulan lainnya. Dalam kondisi jemaat yang seperti ini, hamba Tuhan dituntut untuk menjadi pribadi yang memiliki kepekaan dan kepedulian terhadap jemaatnya.

Seorang hamba Tuhan tidak boleh hanya berdiam diri dan menunggu laporan tentang jemaat yang sedang menghadapi pergumulan. Seorang hamba Tuhan harus secara aktif memiliki inisiatif untuk mencari tahu kondisi yang sedang dihadapi oleh jemaatnya dengan melakukan visitasi atau kunjungan secara aktif kerumah jemaat atau ke rumah sakit. Seorang hamba Tuhan dituntut harus selalu hadir ketika dibutuhkan oleh jemaatnya. ${ }^{2}$ Setelah tahu pergumulan yang dihadapi oleh jemaat, maka hamba Tuhan harus segera bertindak untuk memberikan pertolongan terhadap permasalahan yang dihadapi oleh jemaatnya. Seorang hamba Tuhan dituntut untuk dapat memberikan pengharapan bagi jemaat yang putus asa dan tak berpengharapan. Lebih-lebih ketika jemaat terbaring di rumah sakit karena penyakit kritis. ${ }^{3}$

Ini adalah bentuk perhatian dan kepeduliaan hamba Tuhan sebagaimana yang diharapkan oleh jemaat, sebagaimana yang dilakukan oleh Tuhan Yesus Sang Gembala yang Baik. Gembala yang baik mencari domba yang hilang, membalut domba yang terluka, dan menggendong domba yang letih. Apabila seorang hamba Tuhan lalai melakukan hal ini dalam tugasnya sebagai gembala dalam suatu gereja, maka akan mempengaruhi penilaian terhadap kinerja pelayanannya. Ada jemaat yang merasa tidak puas terhadap hamba Tuhannya karena ia tidak pernah dikunjungi oleh hamba Tuhannya padahal ia sudah cukup lama tidak hadir kegereja

\footnotetext{
${ }^{2}$ Winnifred Fallers Sulivan, A Ministry of Presence: Chaplaincy, Spiritual Care and the Law (Chicago: University of Chicago Press, 2014), 173-174.

${ }^{3}$ John W. Stewart, Envisioning the Congregation, Practicing the Gospel: A Guide for Pastor and Lay Leaders(Grand Rapids: Eerdman, 2015), 236.
} 
karena ada pergumulan hidup yang ia hadapi. Akibatnya ia keluar meninggalkan gereja sebagai protes terhadap hamba Tuhan yang dianggap kurang perhatian terhadap jemaat. ${ }^{4}$ Apabila banyak jemaat yang meninggalkan gereja, maka majelis gereja akan kecewa terhadap hamba Tuhan tersebut yang dinilai kurang menaruh perhatian kepada jemaatnya sehingga menyebabkan anggota jemaat berkurang. Akibatnya gereja pasti tidak akan memakai hamba Tuhan tersebut. Oleh sebab itu, pelayanan visitasi tidak boleh diabaikan dalam pelayanan seorang gembala jemaat.

Hamba Tuhan dalam zaman now harus memiliki kepekaan dan perhatian terhadap jemaatnya. Namun hamba Tuhan juga tidak boleh mengabaikan perhatian kepada keluarganya sendiri. Banyak hamba Tuhan yang sangat perhatian terhadap jemaatnya namun lalai untuk memperhatikan keluarganya. Akibatnya istri dan anakanaknya kecewa dan tidak mendukung pelayanan dari hamba Tuhan tersebut. Hal ini juga dapat menghambat pelayanan seorang hamba Tuhan. Oleh sebab itu, seorang hamba Tuhan harus memberikan perhatian yang seimbang antara kepada jemaat dan kepada keluarga. Apabila hamba Tuhan mampu melakukan hal ini, maka jemaat dan keluarga akan terpuaskan. Alhasil maka pelayanan hamba Tuhan akan kondusif dan produktif karena didukung oleh keluarga dan jemaat.

\section{Hamba Tuhan dan "Orang-orang" Sulit di Gereja}

Di dalam pelayanannya di zaman now, seorang gembala menggembalakan kawanan domba Allah yang memiliki berbagai macam karakter dan sifat. Ada kawanan domba yang baik dan penurut sehingga bisa digembalakan dengan tanpa kesulitan.

\footnotetext{
${ }^{4}$ Neville A Kirkwood,Pastoral Care in Hospitals (Harrisburg, PA: Morehouse Publishing, 1995), 7.
} 
Namun ada juga kawanan domba Allah yang sulit untuk diatur bahkan cenderung menjadi masalah dalam gereja dan khususnya bagi gembala. Seringkali orang-orang yang bermasalah dalam gereja adalah bukan jemaat yang baru sehingga masih bisa dimaklumi karena tingkat kerohaniannya belum dewasa. Justru jemaat yang menjadi sumber masalah bagi hamba Tuhan adalah jemaat yang sudah menjadi anggota gereja dan aktif dalam pelayanan selama bertahun-tahun. Hal ini menyebabkan banyak hamba Tuhan yang mengalami frustrasi menghadapi jemaat yang sulit. Tidak sedikit pula hamba Tuhan yang terlibat konflik dengan jemaat yang bermasalah di dalam gereja. Tidak sedikit hamba Tuhan yang menyerah dalam menghadapi jemaat yang sulit dalam gereja dan memilih untuk menghindari orang-orang tersebut dengan meninggalkan pelayanannya.

Hamba Tuhan dipanggil untuk menggembalakan semua kawanan domba Allah, baik yang penurut atau yang pembuat masalah dalam gereja. Mereka harus dilayani dengan baik oleh hamba Tuhan yang melayani sebagai gembala dalam sebuah gereja. Bagaimana melayani orang-orang sulit dalam gereja? Kesalahan yang terbesar dari hamba Tuhan adalah ingin memperbaiki orang yang bermasalah dalam gereja. Mereka dianggap seperti barang yang rusak dan perlu diperbaiki agar tidak menjadi masalah dalam gereja. Ternyata upaya itu tidak akan pernah dapat berhasil, namun sebaliknya justru akan memperarah kondisi orang tersebut. ${ }^{5}$

Dalam melayani orang-orang yang sulit dalam gereja, seorang hamba Tuhan harus melihat Tuhan Yesus di dalam diri orang yang bermasalah tersebut. Tuhan Yesus Sang Gembala yang Baik sangat mengasihi dan peduli terhadap orang-orang yang bermasalah dalam gereja. Mereka bagaikan domba-domba yang

${ }^{5}$ Chuck DeGroat, Toughest People to Love: How to Understand, Lead, and Love the Difficult People in Your Life-Including Yourselfs(Grand Rapids: Eerdmans, 2014), 177. 
nakal yang perlu diberi perhatian khusus agar mereka dapat kembali ke jalan yang benar. Sebagaimana yang dilakukan oleh Tuhan Yesus terhadap domba-domba yang nakal, pelayanan bagi orang-orang yang bermasalah dalam gereja harus bersifat holistik yang meliputi pelayanan pastoral, pelayanan kepemimpinan gereja, dan pelayanan konseling. ${ }^{6}$

Pelayanan pastoral yang diberikan kepada jemaat yang sulit dalam gereja berkaitan dengan memberi perhatian dan kasih sayang bagi jemaat yang sulit, bukan sikap kebencian atau bahkan bermusuhan. Orang-orang yang bermasalah dalam gereja mungkin kurang mendapatkan perhatian dan kasih sayang dalam keluarganya. Oleh sebab itu, gembala jemaat harus memberikan pelayanan pastoral terhadap jemaatnya yang sulit dengan memberikan apa yang mereka butuhkan yaitu perhatian dan kasih sayang. Apabila hal ini dilakukan dengan benar, maka orang-orang yang sulit pasti akan mengalami perubahan.

Pelayanan kepemimpinan gereja bagi jemaat yang sulit berhubungan dengan keteladan hidup yang diberikan oleh hamba Tuhan kepada jemaatnya, bukan memberi perintah kepada jemaatnya. Hamba Tuhan harus memberi teladan dalam hal kasih dan pengampunan kepada orang-orang yang sulit dalam gereja yang mungkin menyakiti dirinya. Apabila hamba Tuhan tidak dapat mengampuni dan membalas kejahatan yang dilakukan oleh orang lain, maka akan sulit untuk mengubah orang-orang yang bermasalah dalam gereja. Ketika hamba Tuhan mampu memberi pengampunan kepada orang-orang yang bermasalah dalam gereja, maka mereka akan sadar dan pada gilirannya akan berubah menjadi domba-domba yang menurut dan mendukung pelayanan hamba Tuhan.

${ }^{6}$ Chuck DeGroat, Toughest People to Love, 177. 
128 Tantangan Pelayanan Penggembalaan Hamba Tuhan Zaman Now

Pelayanan konseling untuk jemaat yang sulit berkaitan dengan memberi bimbingan psikologis terhadap masalah-masalah psikologis yang dihadapi oleh jemaat Tuhan yang menyebabkan mereka menjadi pribadi yang sulit. Seringkali orang-orang yang menjadi masalah dalam gereja memiliki trauma, kepahitan atau luka batin di masa lalu dan hal itu terus dibawa dalam hidupnya. Luka batin yang belum dipulihkan akan sangat mudah muncul dan ditransferkan kepada orang lain. Akibatnya orang lain atau hamba Tuhan menjadi sasaran ketidakpuasan dari orang-orang yang memiliki luka batin atau kepahitan masa lalu. Hal ini akan terus berulang apabila orang yang bermasalah tidak dipulihkan dari luka batin masa lalunya. Oleh sebab itu, pelayanan konseling psikologis yang disertai dengan doa sangat dibutuhkan oleh jemaat yang sulit dalam gereja.

Pelayanan holistik sangat dibutuhkan oleh orang-orang yang sulit dan bermasalah dalam gereja. Apabila pelayanan holistik ini diberikan dengan tulus dan sungguh-sungguh kepada jemaat yang bermasalah, maka cepat atau lambat orang-orang yang bermasalah di gereja akan mengalami perubahan kearah yang positif. Alhasil hamba Tuhan akan dapat melayani dengan damai sejahtera tanpa diganggu lagi oleh orang-orang yang bermasalah dalam gereja.

Memang melayani orang-orang yang sulit dalam gereja tidak mudah bagi hamba-hamba Tuhan dalam zaman now. Namun hamba Tuhan tidak dapat memilih hanya melayani dan menggembalakan domba-domba yang baik saja. Hamba Tuhan juga harus siap melayani dan menggembalakan domba-domba yang sulit secara holistik, sebagaimana yang dilakukan oleh Tuhan Sang Gembala yang Baik.

\section{Hamba Tuhan dan Kaum LGBT}

Dalam zaman now, gereja berhadapan dengan isu 
penyimpangan seksual yaitu LGBT (Lesbian, Gay, Biseksual, dan Transgender). Isu LGBT yang sebelumnya masih tertutup dan tersembunyi, kini seiring berkembangnya pengetahuan dan teknologi informasi yang memunculkan era keterbukaan yang kajian keilmuannya juga semakin berkembang menjadikan kelompok LGBT mulai lebih terlihat eksistensinya di masyarakat dan juga di dalam gereja.

Ada berbagai macam pandangan gereja terhadap kaum LGBT. Ada gereja yang memandang kaum LGBT sebagai sebuah komunitas yang immoral atau sekelompok orang yang telah melakukan perbuatan dosa karena dianggap telah menyalahi kodrat manusia bahwa persatuan dua cinta hanya diakui antara lelaki dan perempuan saja sehingga gereja dengan tegas menolak dan menghukum mereka. Ada gereja yang menganggap bahwa LGBT adalah sebagai badhabit atau hanya sebuah "lifestyle" yang salah karena perkembangan zaman, globalisasi, dan lingkungan yang mempengaruhi seseorang untuk menjadi LGBT sehingga mereka perlu diterima dan dibina agar mereka dapat kembali kejalan yang benar sesuai dengan orientasi seks mereka. Ada sebagian gereja yang memahami kaum LGBT sebagai orang-orang yang difabel atau cacat sejak lahir seperti orang-orang lain yang mengalami kelainan sejak lahir sehingga gereja menerima mereka dan membimbing mereka untuk tidak jatuh dalam perilaku homoseksual. Ada gereja yang menganggap kaum LGBT adalah orang-orang yang "kurang rohani" dalam komunitas Kristen, sehingga gereja harus menerima mereka dan memberikan bimbingan rohani yang mereka butuhkan agar mereka tidak terus hidup dengan gaya hidup LGBT. Ada pula gereja yang menganggap bahwa kaum LGBT adalah kelompok yang normal layaknya manusia heteroseksual dan memandang penyatuan dua manusia sama seperti penyatuan dua pasang lelaki dan perempuan. Sama-sama memiliki perasaan untuk saling mengasihi, berkomiten 
130 Tantangan Pelayanan Penggembalaan Hamba Tuhan Zaman Now

untuk saling setia dan menerima segala sisi baik dan buruk dari pasangan dalam situasi sehat dan sakit. Gereja yang memiliki pandangan ini menerima kaum LGBT tanpa syaratdan tanpa penanganan yang khusus.

Gereja harus menjadi wadah di mana orang orang yang normal dan kaum LGBT dapat bersatu dalam tubuh Kritus. Kaum LGBT harus dianggap sebagai domba yang hilang dan tersesat yang perlu dicari untuk dibawa kepada Sang Gembala yang Agung yaitu Tuhan Yesus Kristus untuk dipulihkan dari perilaku seksual yang menyimpang dari kaum LGBT. ${ }^{7}$ Gereja tidak boleh menutup pintu dan menolak kaum LGBT karena sikap seperti ini justru akan memperparah kondisi kaum LGBT.

Banyak gereja yang menolak kaum LGBT disebabkan karena gembala jemaat mengalami kesulitan dan tidak tahu bagaimana menangani dan melayani kaum LGBT. Akibatnya banyak kaum LGBT yang tidak ditolong untuk mengenal Kristus Sang Gembala yang Baik dan mengalami pemulihan dari kehidupan dosa mereka. Hamba Tuhan harus mengasihi kaum LGBT sebagaimana manusia lainnya tapi harus tegas dan tidak kompromi terhadap perilaku homoseksual yang dilakukan oleh kaum LGBT. Dengan kata lain, hamba Tuhan harus mengasihi kaum LGBT tapi membenci dosa perilaku homoseksual yang mereka lakukan, sebagaimana sikap Tuhan Yesus Sang Gembala Agung yang mengasihi orang yang berdosa tapi membenci dosa mereka. Prinsip ini harus dimiliki oleh hamba Tuhan agar dapat memberikan pelayanan yang tepat guna bagi kaum LGBT. Kaum LGBT dapat disembuhkan dan dipulihkan ketika mereka merasakan kehangatan sentuhan tangan kasih Kristus Sang Gembala Agung melalui pelayanan hamba Tuhan di dalam gereja.

\footnotetext{
${ }^{7}$ Wendy VanderWal-Gritter, Generous Spaciousness: Responding to Gay Christians in the Church (Grands Rapids: Brazos, 2014), 288.
} 


\section{Hamba Tuhan dan Kaum Muda}

Pelayanan gereja harus menjangkau semua umur tidak terkecuali kaum muda. Kaum muda merupakan generasi penerus bagi sebuah gereja. Gereja yang tidak memiliki kaum muda maka dapat dipastikan bahwa masa depan gereja akan suram. Banyak gereja di Eropa yang tutup dan dijual karena gereja tersebut tidak memperhatikan pelayanan bagi kaum muda di masa lalu. Ternyata fenomena dan realita ini terus terjadi sampai hari ini.

Sangat disayangkan dalam zaman now ini banyak gerejagereja yang kurang memperhatikan pelayanan bagi kaum muda dengan serius. ${ }^{8}$ Gereja hanya melayani kaum muda sebagai sebuah rutinitas saja tanpa melakukan pelayanan yang dapat menyentuh dan memenuhi kebutuhan kaum muda. Banyak gereja-gereja protestan yang kaum mudanya tidak bertumbuh karena gereja gagal untuk secara serius menggarap kaum mudanya. ${ }^{9}$ Akibatnya banyak kaum muda yang keluar meninggalkan gereja untuk pindah ke gereja lain di mana pelayanan kaum muda sangat dinamis dan menjawab kebutuhan kaum muda.

Gereja tidak boleh mengabaikan pelayanan kaum muda kalau gereja tidak ingin masa depannya suram. Gereja perlu memberikan perhatian khusus untuk memenuhi kebutuhan bagi pertumbuhan rohani kaum mudanya. Idealnya gereja harus memiliki hamba Tuhan atau gembala khusus melayani kaum muda sehingga hamba Tuhan tersebut dapat fokus untuk melayani kaum mudanya dengan serius tanpa diganggu oleh pelayanan yang lainnya. Gembala

${ }^{8}$ Cannister Mark, Teenagers Matter: Making Student Ministry a Priority for the Church (Grand Rapids: Baker books, 2013), 254.

${ }^{9}$ Creasy Dean Kenda, and Christy Lang Hearson, How Youth Ministry Can Change Theological Education- If We Let It (Grand Rapids: Eerdmans, 2016), 331. 


\section{Tantangan Pelayanan Penggembalaan Hamba Tuhan Zaman Now}

khusus kaum muda harus memiliki umur yang tidak terlampau jauh dengan kaum muda yang dilayaninya agar dapat mengerti dan mengikuti dinamika kaum muda. Gembala khusus kaum muda juga harus yang belum berkeluarga agar ia dapat bebas melayani kaum muda dengan maksimal tanpa terganggu oleh keberadaan keluarganya.

Hamba Tuhan atau gembala yang khusus menangani kaum muda memiliki tugas dan tanggung jawab yang cukup berat. Untuk itu, seorang hamba Tuhan yang menangani kaum muda harus belajar mengerti karakteristik kaum muda yang penuh dinamika. Dengan memahami karakteristik kaum muda maka gembala kaum muda akan mengerti apa yang dibutuhkan oleh kaum muda. Setelah mengerti kebutuhan kaum muda, maka gembala kaum muda akan dapat melayani kaum muda secara tepat dan cermat, sehingga kaum muda merasa dipuaskan dan akan merasa nyaman dan bergerak secara aktif untuk mengembangkan pelayanan kaum muda dalam gereja.

Seorang gembala kaum muda juga dituntut untuk memiliki kreatifitas yang tinggi dalam melayani kaum muda yang penuh dinamika dan selalu ingin sesuatu yang baru, variatif, dan menantang. Kaum muda sangat mudah bosan dengan kegiatan gereja yang monoton. Gembala kaum muda harus terus berinovasi dalam merancang program pelayanan dan aktifitas yang relevan bagi kaum muda. Dengan demikian kaum muda akan tertarik untuk hadir dan tidak "malu" untuk membawa teman-temannya untuk hadir dalam persekutuan kaum muda. Apabila hal ini terealisasi, maka masa depan gereja akan gemilang dan gereja tidak akan takut kekurangan jemaat. Oleh sebab itu, pelayanan terhadap kaum muda gereja harus diselaraskan dengan kondisi kaum muda dalam zaman now. 


\section{PENUTUP}

Menjadi hamba Tuhan adalah suatu kehormatan karena menjadi rekan kerja Allah dalam menggenapi misi Allah untuk menghadirkan kerajaan-Nya dalam dunia ini. Ketika seseorang merespons panggilan Tuhan menjadi hamba Tuhan, maka ia harus siap untuk menghadapi tantangan dan tuntutan yang tidak mudah dalam pelayanan. Tuntutan dan tantangan pelayanan dalam zaman now makin besar dan kompleks.

Apabila hamba Tuhan menyerah kalah dan mundur tatkala menghadapi tantangan dan tuntutan dalam pelayanan, maka ia tidak layak bagi Tuhan. Sebaliknya, apabila seorang hamba Tuhan mampu bertahan menghadapi dan menjawab tantangan dan tuntutan dalam pelayanan, maka baginya tersedia mahkota kehidupan yang Tuhan telah sediakan bagi hamba-hamba-Nya yang setia.

Tuhan Yesus Sang Gembala Agung telah memberikan teladan kesetiaan dalam pelayanan. Banyak tantangan dan tuntutan yang Ia hadapi dalam pelayanan-Nya. Namun Tuhan Yesus melakukan pelayanan secara maskimal bahkan rela mengorbankan diri-Nya bagi domba-domba-Nya. Allah berkenan kepada pelayanan yang telah dilakukan oleh Tuhan Yesus dan memberikan penghargaan yang sangat tinggi kepada Tuhan Yesus (Filipi 2:910). Hamba-hamba Tuhan dalam zaman now harus meneladani Kristus yang melayani dengan tidak takut dan mudah menyerah tatkala menghadapi tantangan dan tuntutan dalam melayani pekerjaan Tuhan. 


\section{DAFTAR RUJUKAN}

\section{Buku:}

Cosgrave, Charles $\mathrm{H}$ and Edgerton, W. Dow. In Other Words: Incarnation Translation for Preaching. Grand Rapids: Eerdmans, 2007.

Degroat, Chuck. Toughest People to Love: How to Understand, Lead, and Love the Difficul People in Your Life-Including Yourselfs. Grand Rapids: Eerdmans, 2014.

Kenda, Creasy Dean and Hearson, Christy Lang. How Youth Ministry Can Change Theological Education-If We Let It. Grand Rapids: Eerdmans, 2016.

Kirkwood, Neville A. Pastoral Care in Hospitals. Harrisburg, PA: Morehouse Publishing, 1995.

Mark, Cannister. Teenagers Matter: Making Student Ministry a Priority for the Church. Grand Rapids: Baker Books, 2013.

Moon, Garry W., and David G. Benner, eds. Spiritual Direction and the Care of Souls: A Guide to Christian Approaches and Practices. Downers Grove: Intervarsity Press, 2004.

Oden, Thomas C. Pastorals Theoology: Essensials of Ministry, SanFransisco: HarperCollin Publishers, 1983.

Stewart, John W. Envisioning the Congregation, Practicing the Gospel: A Guide for Pastor and Lay Leaders. Grand Rapids: Eerdman, 2015. 
Sulivan, Winnifred Fallers. A Ministry of Presence: Chaplaincy, Spiritual Care and the Law. Chicago: University of Chicago Press, 2014.

VanderWal-Gritter, Wendy. Generous Spaciousness: Responding to Gay Christians in the Church. Grands Rapids: Brazos, 2014.

Van Harn, Roger E. Preacher, Can You Hear Us Listening? Grand Rapids: Eerdmans, 2005.

\section{Jurnal:}

Leede, H. de and Stark, F. Protestant Preaching: Its Strength and Weaknesse.Calvin Theological Journal Vol 50. No.1, 2015. 